
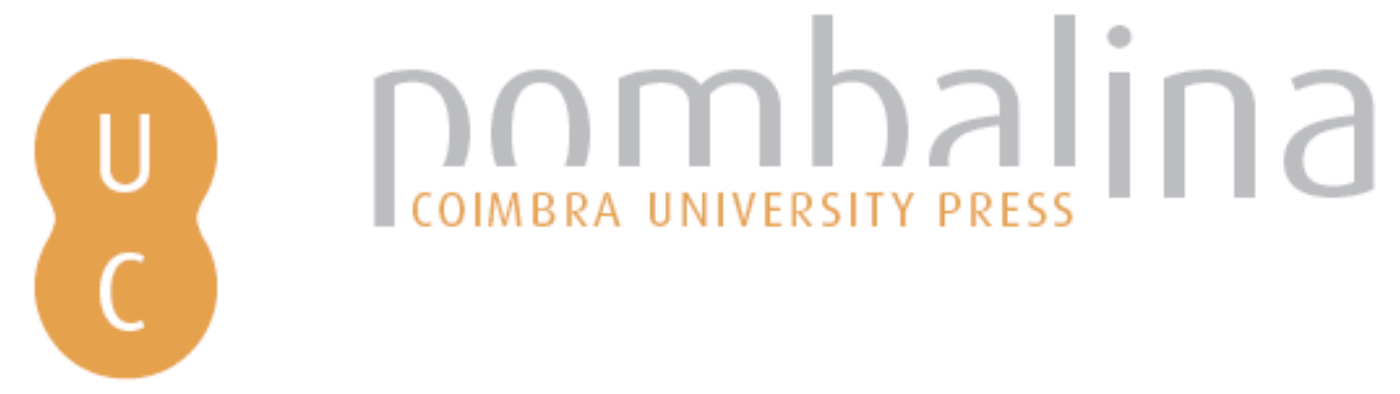

\title{
Unidades de execução: a ténue fronteira entre instrumentos de programação do uso do solo e de planeamento municipal
}

\author{
Autor(es): $\quad$ Reis, Júlia S. C. \\ Publicado por: Imprensa da Universidade de Coimbra \\ URL \\ persistente: URI:http://hdl.handle.net/10316.2/30826 \\ DOI: $\quad$ DOI:http://dx.doi.org/10.14195/978-989-26-0244-8_44 \\ Accessed : $\quad$ 26-Apr-2023 15:19:38
}

A navegação consulta e descarregamento dos títulos inseridos nas Bibliotecas Digitais UC Digitalis, UC Pombalina e UC Impactum, pressupõem a aceitação plena e sem reservas dos Termos e Condições de Uso destas Bibliotecas Digitais, disponíveis em https://digitalis.uc.pt/pt-pt/termos.

Conforme exposto nos referidos Termos e Condições de Uso, o descarregamento de títulos de acesso restrito requer uma licença válida de autorização devendo o utilizador aceder ao(s) documento(s) a partir de um endereço de IP da instituição detentora da supramencionada licença.

Ao utilizador é apenas permitido o descarregamento para uso pessoal, pelo que o emprego do(s) título(s) descarregado(s) para outro fim, designadamente comercial, carece de autorização do respetivo autor ou editor da obra.

Na medida em que todas as obras da UC Digitalis se encontram protegidas pelo Código do Direito de Autor e Direitos Conexos e demais legislação aplicável, toda a cópia, parcial ou total, deste documento, nos casos em que é legalmente admitida, deverá conter ou fazer-se acompanhar por este aviso.

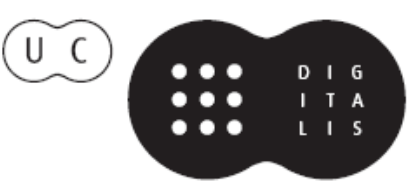




\section{TRUNFOS DE UMA}

\section{EOGRAFIA ACIVA}

\section{DESENVOLVIMENTO LOCAL,}

AMBIENTE,

ORDENAMENTO

E TECNOLOGIA

Norberto Santos

Lúcio Cunha

COORDENAÇÃO 
Júlia S. C. Reis

Unidade de Execução: Instrumento Intercalar entre o Planeamento e a Gestão Urbanística

\section{UNIDADES DE EXECUÇÃO: A TÉNUE FRONTEIRA ENTRE INSTRUMENTOS DE PROGRAMAÇÃO DO USO DO SOLO E DE PLANEAMENTO MUNICIPAL}

As Unidades de Execução estão previstas desde 1999, na versão original do Regime Jurídico dos Instrumentos de Gestão Territorial (RJIGT), o Decreto-Lei n. ${ }^{\circ}$ 380/99 de 22 de Setembro.

Artigo 119. ${ }^{\circ}$ Sistemas de execução

2 - (..) as Unidades de Execuçâo podem ser delimitadas pela câmara municipal por iniciativa própria ou a requerimento dos proprietários interessados.

Artigo $1200^{\circ}$ Delimitação das unidades de execução

1 - A delimitação de unidades de execução consiste na fixação em planta cadastral dos limites físicos da área a sujeitar a intervenção urbanistica e com identificação de todos os prédios abrangidos.

2 - As unidades de execução deverão ser delimitadas de forma a assegurar um desenvolvimento urbano harmonioso e a justa repartição de benefícios e encargos pelos proprietários abrangidos, devendo integrar as áreas a afectar a espaços públicos ou equipamentos previstos nos planos de ordenamento.

3 - As unidades de execução podem corresponder a uma unidade operativa de planeamento e gestáo, à área abrangida por um plano de pormenor ou a parte desta.

4 - Na falta de plano de pormenor aplicável à área abrangida pela unidade de execução, deve a câmara municipal promover, previamente à aprovação, um periodo de discussáo pública em termos análogos aos previstos para o plano de pormenor.

Nas diversas redacçóes ao RJIGT que entretanto foram publicadas não houve alteraçóes no corpo do texto dos artigos que referenciam este instrumento.

Apesar dos 10 anos de vigência do RJIGT, as Unidades de Execução não materializaram muitos ensaios. Uma breve pesquisa sobre esta temática revela que muito pouco se tem escrito sobre este instrumento e as poucas experiências conhecidas ainda se encontram a ser executadas. ${ }^{1}$

As Unidades de Execução correspondem a um instrumento intercalar entre o planeamento e a gestão urbanística. Não são, no entanto, instrumentos de planeamento e não

\footnotetext{
1 Das pesquisas efectuadas somente foi obtida informação substancial sobre a Unidade de Execução desenvolvida para a UOPG 1 (Unidade Operativa de Planeamento e Gestáo) Avenida de Nun'Alvares no Porto, elaborada pela Câmara Municipal, com a colaboraçáo do Prof. Jorge Carvalho da Universidade de Aveiro.
} 
gozam da eficácia plurisubjectiva ${ }^{2}$ que àqueles é reservada. Mas a delimitação de uma Unidade de Execução constitui um acto administrativo real, que define os traços essenciais e basilares da intervençáo a levar a cabo em determinada área, ainda que não esgote ou antecipe os projectos em concreto a realizar (Lopes 2008).

Por este motivo a delimitação da Unidade de Execução "deve ir além da mera delimitação, em planta cadastral, dos limites físicos da mesma, estabelecendo uma solução (programa) urbanistica de base na qual o municipio garanta ainda, um traçado regulador, que estabeleça as desejáveis articulaçóes com envolvente e pré-existências." (Oliveira 2008).

Deve também definir os "usos multifuncionais e compativeis a concretizar na mesma; uma explicitação - ainda que não necessariamente identificação em termos de localização territorial - das áreas a afectar a espaços públicos ou equipamentos previstos nos planos de ordenamento; e uma definição dos encargos e da dimensão ou extensão desejável dos mesmos a ser assumidos pelos vários intervenientes nas operaçóes urbanisticas a levar a cabo para a sua concretizaçâo.» (Oliveira 2008).

"Por se encontrar ligada aos vários sistemas de execução dos planos e por implicarem uma regulamentação global da sua área de intervenção, as Unidades de Execução são espaços privilegiados de concertação e contratualização de interesses, servindo, simultaneamente, como mecanismos incentivadores ou desincentivadores de projectos urbanisticos determinados.» (Lopes 2008).

Importa que a Unidade de Execução possua uma dimensão adequada para permitir um projecto urbano integrado, que assegure os objectivos do desenvolvimento urbano harmonioso e a justa repartição de benefícios e encargos pelos proprietários abrangidos na Unidade (cfr. n. ${ }^{\circ} 2$ do art. $120^{\circ}$ do RJIGT), com base nos três sistemas legalmente previstos (compensação, cooperação ou imposiçáo administrativa $)^{3}$, bem como a localizaçáo dos terrenos a integrar futuramente no domínio público para equipamentos e zonas verdes, em face da programação estipulada pelo Município e da gestão das suas prioridades. ${ }^{4}$

\footnotetext{
${ }^{2}$ Vinculando para além das entidades públicas, também directa e imediatamente os particulares, cfr. art. $3^{\circ}$ do RJIGT.

${ }^{3}$ De acordo com o disposto no art. $122^{\circ}$ do RJIGT o sistema de compensação é da responsabilidade dos proprietários abrangidos pela Unidade de Execução delimitada, que devem organizar-se através de um processo associativo. A perequação dos encargos e benefícios é definida entre os titulares, na proporção do valor atribuído aos seus direitos, por exemplo mediante celebração de contrato de urbanização. Neste sistema devem prestar ao Município as compensaçóes devidas de acordo com as regras previstas nos Planos em vigor para a área de intervenção da Unidade. O sistema de cooperação, previsto no art. $123^{\circ}$ do RJIGT é concebido como sistema de iniciativa municipal, mas pressupondo a cooperaçáo dos proprietários interessados. Os direitos e obrigaçôes dos titulares abrangidos pela delimitação da Unidade de Execução são definidos por contrato de urbanização que poderá ter maior ou menor intervenção municipal em face dos acordos que se forem alcançando para a execução do programa-base da Unidade. Em última análise poderá haver substituição dos proprietários que não subscreverem o acordo pelo Município, mediante mecanismos expropriativos. Por sua vez, no sistema de imposição administrativa, cfr. art. 124º do RJIGT, o Município assume integralmente a execuçâo do estipulado no programa-base da Unidade, actuando directamente ou concessionando a urbanização através de um concurso público.

${ }^{4}$ "Tal significa que a área da Unidade de Execução não deve corresponder, em regra, ao limite da propriedade de um só interessado. No entanto, admite-se que uma Unidade de Execução possa corresponder a um só prédio, da propriedade do mesmo titular, quando aquele tenha uma dimensão, em termos de área, adequada à concretização de um projecto urbano que, do ponto de vista da ocupação da urbe, se possa considerar integrada e potenciadora de um crescimento urbano harmonioso. Numa situação destas não terá, naturalmente de ocorrer, no interior da Unidade de Execução a repartição de benefícios e encargos. Subsiste o reconhecimento de que a propriedade de cada individuo não é a unidade territorial apropriada para a concretização de intervençóes urbanísticas racionais e integradas sendo
} 
No entanto «nunca poderá a delimitação da Unidade de Execução pressupor um projecto concreto que não aquele que vier a ser acertado com os interessados", pois não estamos "no âmbito de um instrumento de planeamento, em relação ao qual o município disporia de poderes para determinar, de forma unilateral, o desenho urbano.» (Oliveira 2008).

A celeridade e flexibilidade das Unidades de Execução contrapóem-se à natureza regulamentar do Plano de Pormenor (PP) e do seu conteúdo material e documental. A concertaçáo e a contratualização nos projectos carecem de alguma margem de modelação, essenciais quer no momento da elaboração do programa-base, quer no da execução da soluçáo urbanística, desde que os objectivos estratégicos da intervenção não sejam colocados em causa. A natureza regulamentar do PP dificulta a concertaçáo, para além de que qualquer alteraçáo à sua proposta, definida com minúcia, implica a necessidade de desencadear procedimentos de alteração, no quadro do RJIGT, que encerram sempre alguma morosidade, ou corre-se o risco de violação do Plano com a consequente nulidade dos actos praticados.

As recentes alteraçóes ao RJIGT trazidas pelo Decreto-Lei n. ${ }^{o}$ 316/2007 de 16 de Setembro, na redacção dada pelo Decreto-Lei n. ${ }^{\circ}$ 46/2009 de 20 de Fevereiro, vieram introduzir um conjunto de aspectos particularmente relevantes nesta matéria procurando trazer alguma maleabilidade aos PP aproximando-os das Unidades de Execução.

$\mathrm{O}$ facto de os instrumentos de planeamento municipal poderem ser objecto de contratualização nos termos do art. $^{\circ} 6^{\circ}-\mathrm{A}$ e $6^{\circ}-\mathrm{B}$ do RJIGT, aliado à circunstância de os mesmos Planos, em certas condiçóes poderem proceder directamente à transformação fundiária da sua área de intervenção, dispensando posteriormente actos de controlo preventivo das operaçóes urbanísticas que a visam alcançar (art. 920-A e 131 ${ }^{\circ}$, no 10 do RJIGT) apresenta-se como uma óbvia vantagem na flexibilização destes instrumentos de planeamento.

Como o próprio legislador afirma no preâmbulo do diploma as " (...) exigências de simplificação e eficiência levam ao reconhecimento expresso da possibilidade dos planos de pormenor com um conteúdo suficientemente denso procederem a operaçóes de transformação fundiária relevantes para efeitos de registo predial e inscrição matricial, dispensando-se um subsequente procedimento administrativo de controlo prévio. Com efeito, reconhecida a identidade funcional entre muitos planos de pormenor e as operaçóes de loteamento e reparcelamento urbano e de estruturação da compropriedade, justifica-se, salvaguardada a autonomia da vontade dos proprietários, que o plano de pormenor possa fundar directamente a operação de transformação fundiária, seja o fraccionamento ou o emparcelamento das propriedades (...)"

Com a introdução desta possibilidade, no âmbito deste Regime Jurídico, e não no quadro de uma Lei de natureza excepcional, como é o caso da Lei das Áreas Urbanas de Génese Ilegal (AUGI) ${ }^{5}$ onde esta possibilidade ocorre desde 1999, assiste-se ao princípio da operacionaliza-

fundamental incentivar (e empurrar) os proprietários para processos associativos com vista a concretizar projectos urbanisticos de dimensão adequada a um crescimento harmonioso da urbe.» (Oliveira 2008).

${ }^{5} \mathrm{Na}$ redacção do art. $31^{\circ}$ da Lei n. ${ }^{\circ}$ 165/99 de 14 de Setembro, a reconversão municipal mediante Plano de Pormenor (PP) segue os trâmites do Decreto-Lei n. ${ }^{\circ}$ 380/99 de 22 de Setembro. Quiçá preciosismo linguístico ou resultado de um esforço de compatibilização entre os diferentes diplomas aplicáveis ao direito do urbanismo, o facto é que na redacçáo original do artigo em apreço (Lei n. $91 / 95$ de 02 de Setembro) se referia que a reconversáo municipal era prosseguida através da elaboração de PP de Reconversão: $P P R$. Náo obstante tal designação ter sido entretanto alterada, facto é que, independentemente da denominação (PP de reconversão ou reconversão mediante elaboração de PP), a mais importante inovação chegou na redacção de 1999, através da qual, e de acordo com o disposto no n. ${ }^{\circ}$ do art. $31^{\circ}$, a certidão do Plano substitui o alvará de loteamento para efeitos de registo predial, ou seja, em termos práticos, o PPR assume, também, o papel de Título de Reconversão, 
ção da figura dos PP, uma vez que, nos termos e para os efeitos do disposto no art. $91^{\circ}-\mathrm{A}$ e art. 92º-B do RJIGT, a certidáo do Plano, uma vez emitida, passará a constituir titulo bastante para a individualização no registo predial dos prédios resultantes das operaçóes de loteamento, estruturação da compropriedade ou reparcelamento previstas no Plano.

\section{QuANDO AS UNIDAdes de EXECUÇÃO OCORREM FORA dOS PlanOS DE PORMENOR}

As Unidades de Execução podem ocorrer no interior ou fora da área de intervenção de $\mathrm{PP}$, no entanto é nas Unidades de Execução náo precedidas de Plano que se colocam maiores dúvidas sobre o seu procedimento, designadamente quanto aos elementos que devem fazer parte da deliberação da sua delimitação.

Quando ocorrem fora de Planos e com vista a ultrapassar o argumento de que a adopção de uma qualquer solução urbanística vinculativa se confronta com o princípio geral da tipicidade $^{6}$ dos Planos, devem (Carvalho 2008):

- associar à "Unidade de Execução um programa urbanístico (desenhado) com pormenor suficiente para permitir a discussáo pública mas com a flexibilidade necessária à desejável futura concertação com proprietários e outros eventuais promotores;

- assumir que tal programa urbanistico tem uma natureza orientadora, não vinculativa podendo, se referenciado ao quadro legal em vigor, ter valor igual ao de uma informação prévia no quadro do Regime Jurídico da Urbanização e Edificação ${ }^{7}$ relativa a um futuro e desejável loteamento;

- estabelecer que a discussáo pública acontecerá em duas fases: a do programa urbanístico, com a delimitação de Unidade de Execução e a correspondente ao loteamento, quando os parceiros o sujeitarem à aprovação municipal.»

Exigir que no momento da delimitação das Unidade de Execução se defina com rigor o projecto a adoptar, dificultaria o funcionamento dos sistemas de execução, na medida em que a contratualização e a celebração dos contratos de urbanização entre proprietários e entre estes e o Município podem levar a que se redesenhe o projecto preliminarmente divisado, tendo em consideração o princípio da procura da máxima cooperação.

"Adoptando procedimento similar ao que a lei exige para o Plano de Pormenor nas duas fases da discussão, cumprir-se-iam todos os objectivos e disposiçóes legais e sublinhar-se-ia a natureza processual dos sistemas de execução, com várias etapas, participadas pelos parceiros e sujeitas a discussão pública.» (Carvalho 2008).

situação que se mantém na actual redacção da Lei das AUGI (Lei n. ${ }^{\circ}$ 10/2008 de 20 de Fevereiro). O PP ao abrigo da Lei das AUGI, apresenta-se como uma solução do tipo: $2 \mathrm{em} \mathrm{1,} \mathrm{constituindo} \mathrm{a} \mathrm{emissão} \mathrm{da} \mathrm{certidão} \mathrm{do}$ $P P R$ à emissão do Título de Reconversão, o que equivale à emissão de um alvará de loteamento, como supra mencionado. O PPR assume pois as funções de um PP tradicional (concepção do espaço urbano que define os usos do solo e condiçóes gerais das edificaçóes) e, por outro lado, tem também as atribuiçóes de um alvará de loteamento (instrumento que divide de facto, e de direito, a propriedade em lotes). (Reis, Caiado 2002)

${ }^{6}$ A Administração não pode elaborar os Planos que entender, mas apenas aqueles que a Lei prevê de modo típico, cabendo a esta indicar a designação e o conteúdo mínimo dos Planos, bem como descrever o respectivo procedimento de elaboração.

${ }^{7}$ Decreto-Lei n. ${ }^{\text {555/99 de } 16}$ de Dezembro, com as alteraçôes introduzidas pela Lei n. ${ }^{\circ}$ 60/2007 de 4 de Setembro. 
Subsiste uma questão importante: a lei não previu formas de «suspensão dos procedimentos de gestâo urbanistica como resultado do decurso do procedimento de delimitação de uma Unidade de Execução, nem a possibilidade de medidas preventivas para o efeito, pelo que não há como obstar à prática de actos finais de procedimentos que se encontrem em curso, decorridos os prazos legais de decisão.» (Lopes 2008).

\section{CONTEÚdo DOCUMENTAL E MATERIAL DA UNIDADE DE EXECUÇÃO E SUA TRAMITAÇÃO PROCEDIMENTAL}

Refira-se que o RJIGT não faz qualquer referência ao contudo material e documental deste instrumento, permitindo alguma liberdade na escolha dos elementos que compóem o programa-base.

Cada Município pode, em face das intervençôes a concretizar, estruturar a melhor metodologia em face do território que possui, dos parceiros a envolver na concretização dos projectos, e sistema de planeamento em vigor para o seu território.

Carvalho 2008 apresenta uma proposta de organização de Unidade de Execução que constitui um documento de trabalho muito interessante e que poderá servir de base para o início dos procedimentos de elaboração deste tipo de instrumento.

A UOPG1 (Unidade Operativa de Planeamento e Gestão) Avenida de Nun’Alvares no Porto, é um bom teste à metodologia proposta por Carvalho 2008, no entanto como ainda não se encontra concluída a sua execução, a avaliação de resultados só será possível, em momento posterior. Também o Município de Oliveira de Azeméis se encontra a desenvolver uma Unidade de Execuçáo assente na proposta de estruturação de procedimentos elencada por Carvalho 2008, ainda que por comparação com o grau de desenvolvimento da Unidade de Execução do Município do Porto, se encontre ainda numa fase incipiente do processo.

Tendo por base a proposta apresentada por Carvalho 2008 e após consulta da proposta de Unidade de Execução da UOPG1 - Avenida de Nun'Alvares no Porto, elaborada pela Câmara Municipal, perspectivam-se os seguintes conteúdos:

- Planta que identifica a delimitação física da Unidade de Execução e prédios abrangidos; ${ }^{8}$

\footnotetext{
${ }^{8} \mathrm{Na}$ delimitação da Unidade reside a dificuldade em obter informação sistematizada e actualizada sobre os prédios abrangidos na área de intervenção uma vez que para a obtenção desta informação é necessário correlacionar informação proveniente das Conservatórias do Registo Predial, Finanças e Instituto Geográfico Português. A dispersão da informação por estas Instituiçôes dificulta o processo de delimitação e posterior concertação e contratualizaçáo. Em 2007 com a publicação do Decreto-Lei n.o 224/2007 de 31 de Maio é aprovado o regime experimental da execução, exploração e acesso à informação cadastral visando a criação do Sistema Nacional de Exploração e Gestão de Informação Cadastral (SINERGIC). Este sistema visa condensar de forma sistemática a realidade factual da propriedade imobiliária com o registo predial, as inscriçôes matriciais e as informaçóes cadastrais. Como refere o próprio diploma no seu preâmbulo "... o reconhecimento dos limites da titularidade da propriedade $e$ das respectivas vicissitudes, por via da articulação entre as informaçöes cadastrais, do registo predial e fiscais, constitui um instrumento indispensável à execução das políticas públicas de ordenamento do território e das demais políticas públicas com impacte territorial, designadamente no domínio do ambiente e da preservação dos recursos naturais, da agricultura e florestas, das obras públicas e demais infra-estruturas, constituindo, também um instrumento de regulação do mercado imobiliário e de repartição das mais-valias fundiárias.» Com a operacionalização deste Sistema ultrapassa-se uma das
} 
- Relatório contendo a fundamentação da proposta da futura solução urbanística, integrando:

1. Caracterização e Diagnóstico da área de intervenção:

- Enquadramento territorial;

- Enquadramento em Planos de hierarquia superior, cartas e estudos que o acompanham, bem como a identificação de todas as condicionantes e restriçóes de utilidade pública;

- Antecedentes interessantes à contextualização temporal da intervenção;

- Caracterização fundiária;

- Caracterização morfotipológica e funcional do tecido urbano existente e envolvente;

- Identificação dos valores em presença patrimoniais, culturais e naturais;

- Identificação das carências (espaços verdes e de equipamentos);

- Compromissos urbanísticos;

2. Princípios orientadores da solução urbanística e do processo de implementação:

A. Solução urbanística de base:

- Princípios orientadores da solução urbanística de base;

- Intençóes relativas à estrutura viária/malha urbana existente e futura;

- Condiçốes de fluidez e circulação a salvaguardar;

- Quantificação (e condições de localização/inserção) das áreas de utilização colectiva (equipamentos e áreas verdes) gerais e locais a prever;

- Definição da solução urbanística (espaço público, opções morfotipológicas e edificabilidade) e dos estudos a desenvolver necessários à sua implementação.

B. Processo de implementação:

- Escolha do(s) sistema(s) de execução e regras básicas para o envolvimento dos agentes no processo;

- Área(s) a sujeitar a operaçôes urbanísticas e suas condiçôes;

- Área(s) a sujeitar a outras operaçóes urbanísticas, por exemplo no tecido edificado pré-existente, nomeadamente de construção, reconstrução com ou sem preservação de fachada, ampliação, alteração, conservação ou demolição e em que condiçóes;

- Condiçóes aplicáveis à área a intervir no âmbito de outros projectos, nomeadamente de financiamentos no âmbito do Quadro de Referência Estratégica (QREN 2007/2013);

- Programa de Execução e Plano de Financiamento.

Durante o decurso da elaboração da versão preliminar do programa base da Unidade de Execução decorre o período de concertação com os proprietários envolvidos na área de intervenção, com vista a firmar acordos para o desenvolvimento da versão final do programa a submeter à Reunião de Câmara e a discussão pública.

Os prazos para o desenvolvimento da Unidade de Execução são mais reduzidos do que para a elaboração de um PP, pelo facto do seu conteúdo documental/material ser mais reduzido e por náo estar sujeito a pareceres vinculativo das entidades para o seu desenvolvimento. Os pareceres das entidades ficam afastados para o momento da concretizaçáo, nomeadamente da(s) operação(óes) urbanísticas, sem os quais não é possível ser aprovado em Câmara.

principais dificuldades no sistema de planeamento, ordenamento e gestáo territorial - qual a configuração jurídica do terreno, quantos titulares possui e a quem pertencem os solos em Portugal? 
Ao nível da tramitação procedimental da Unidade, perspectiva-se:

1. Deliberação de Câmara Municipal que aprove a delimitação da Unidade de Execução e do seu programa base, bem como delibere proceder à abertura da discussão pública sobre o mesmo (cfr. n. ${ }^{\circ} 4$ do art. $120^{\circ}$, conjugado com n. ${ }^{\circ} 4$ do art. $77^{\circ}$ do RJIGT). Tratando-se de um instrumento operativo/executório e não de um Instrumento de Gestão Territorial, a sua aprovação é da competência da Câmara Municipal;

2. Período de discussão pública de 22 dias (mínimo), cfr. n. ${ }^{\circ}$ do art. $120^{\circ}$ do RJIGT que refere a publicitação em Diário da República, comunicação social e página da internet, com antecedência de 5 dias relativo ao início do período de discussáo pública;

3. Ponderação e elaboração de relatório da discussão pública, cfr. $n .^{\circ} 5$ do art. $77^{\circ}$ do RJIGT;

4. Divulgação dos resultados da discussão pública, cfr. n. ${ }^{\circ} 5$ e 6 do art. $77^{\circ}$ do RJIGT;

5. Aprovação em Reunião de Câmara da versão final da proposta de delimitação da Unidade de Execução, reformulada, se necessário, na sequência da ponderação dos resultados da discussão pública;

6. Envio à Assembleia Municipal para conhecimento do conteúdo da Unidade de Execução;

7. Execução da Unidade em conformidade com a solução determinada no programa base.

\section{DESAFIOS NO FUTURO DAS UNIDADES DE EXECUÇÃO}

O futuro das Unidades de Execução enquanto instrumento de gestão territorial depende da proliferação de experiências disseminadas pelo território, de modo a recolher práticas de actuação que possam ser discutidas e reproduzidas.

Os dez anos de vigência deste instrumento não produziram um grande número de ensaios, havendo alguma resistência na sua adopção quando comparada aos PP, cujos conteúdos e tramitação se encontram perfeitamente definidos no quadro legal vigente.

É precisamente neste contexto de experimentaçáo de novas abordagens subjacentes aos processos de planeamento, na óptica da conciliação e concertação de interesses públicos e destes com os interesses privados, associados a uma liberdade conceptual, principalmente ao nível do conteúdo programático, que reside o interesse deste instrumento.

No entanto, as Unidades de Execuçáo podem ainda, no quadro do RJIGT, reforçar a sua componente de programação e execução associando à sua delimitação alguma regulação específica sobre regimes de Administraçáo Conjunta dos prédio(s) inserido(s) na delimitação da Unidade, em moldes semelhantes aos estipulados na Lei das AUGI, ou mais recentemente, na revisão do Regime Jurídico da Reabilitação Urbana, pese embora neste regime ainda se aguarde a publicação de decreto regulamentar que defina o regime jurídico a aplicar.

Na Lei das AUGI a Administração Conjunta é constituída por uma assembleia de proprietários, uma comissão de administração e uma comissão de fiscalização com competências distintas. O regime da Administração Conjunta neste quadro legal encontra-se bastante regulado estando definida a composição, o sistema de votação, o modo de convoca- 
ção, o funcionamento das assembleias, bem como a sua gestão financeira. Esta Administração Conjunta é instituída para cada AUGI delimitada e possui poderes para representar os titulares de direitos na área da AUGI na prática de diversos actos, nomeadamente os necessários à tramitação dos processos de reconversão urbanística, bem como celebrar contratos de urbanização, constituir e movimentar contas bancárias.

Se para as Unidades de Execução for elencado um sistema semelhante, assiste-se, sem dúvida, a uma alteração de fundo no processo de organização de parcerias, e da definição do sistema de execução para as futuras intervençóes.

Uma última consideração para os geógrafos que trabalham na área do planeamento, ordenamento e gestáo urbanística. O desafio está lançado na procura de novos actores neste quadro de actuação, onde o geógrafo, tal como as restantes formaçóes académicas, têm lugar, assim estejam dispostos a encontrar o seu equilíbrio e construir as bases de trabalho que permitem discutir os problemas e principalmente propor as soluçóes.

Esperemos, então, que o desafio se cumpra.

\section{REFERÊNCIAS BIBLIOGRÁFICAS}

Carvalho, Jorge 2008 'Organização das unidades de execução', Revista Direito Regional e Local, n. o 2, pp. 33-40. Lopes, Dulce 2008 'Planos de pormenor, unidades de execução e outras figuras de programaçáo urbanística em Portugal', Revista Direito Regional e Local, n. ${ }^{\circ} 3$, pp. 8-17.

Oliveira, Fernanda Paula 2008 'As virtualidades das unidades de execução num novo modelo de ocupação do território e outras figuras de programação urbanística em Portugal' , Revista Direito Regional e Local, n. ${ }^{\circ}$, pp. 17-31.

Reis, Júlia; Caiado, Teresa 2002 'Planos de Pormenor de Reconversão. Ousar Usar a Imaginação’ Revista Sociedade e Território, n.o 33, pp. 57-64 